\title{
Effects of Er and Zr additions on precipitation and recrystallization of Al-Mg alloy
}

\author{
Wanhui Zhao ${ }^{1, a}$, Shengping Wen ${ }^{1, b,}$, Wei Wang ${ }^{1, c}$, Hui Huang ${ }^{1, d}$, Zuoren Nie Ne $^{1, e}$ \\ ${ }^{1}$ School of Material Science and Engineering, Beijing University of Technology, Pingleyuan 100, \\ Chaoyang District, Beijing 100124, People's Republic of China \\ azhaowanhui@emails.bjut.edu.cn, ${ }^{b^{*}}$ spwen@bjut.edu.cn, ${ }^{\mathrm{c}}$ wangwei@bjut.edu.cn, \\ dhuanghui@bjut.edu.cn, ezrnie@bjut.edu.cn
}

Keywords: Al-Mg alloy; precipitation; recrystallization; Erbium; Zirconium

\begin{abstract}
The effects of Er and $\mathrm{Zr}$ on the precipitation and recrystallization of $\mathrm{Al}-\mathrm{Mg}$ alloy was investigated using hardness testing,optical microscopy and transmission electron microscopy. The results show that Al-Mg-Er-Zr alloy has a markedly hardening effect during isochronal annealing. The recrystallization temperature of the Al-Mg-Er-Zr alloy is significantly higher than that of $\mathrm{Al}-\mathrm{Mg}$ alloy, owing to the presence of nanosized and coherent $\mathrm{Al}_{3}(\mathrm{Er}, \mathrm{Zr})$ precipitates.
\end{abstract}

\section{Introduction}

Aluminium alloys with magnesium as the major alloying element constitute a group of non-heat treatable alloys with medium strength, high ductility,excellent corrosion resistance and weldability. Unlike the heat treatable alloys, these materials derive their strength primarily from solid solution strengthening by $\mathrm{Mg}$ and strain hardening. However, high levels of $\mathrm{Mg}$ cause processing challenges and the susceptibility to stress corrosion cracking [1,2]. An effective alternative method, minor-alloying, addition of small amount of alloying elements such as $\mathrm{Sc}$ and $\mathrm{Zr}$, is used to increase the strength and thermal stability of $\mathrm{Al}-\mathrm{Mg}$ alloys by the formation of $\mathrm{Al}_{3} \mathrm{Sc}$ and $\mathrm{Al} 3(\mathrm{Sc}, \mathrm{Zr})$ dispersoids [3-5].

The heavy rare-earth element $\mathrm{Er}$, which is similar to $\mathrm{Sc}$ but more cheaper, has been shown to improve the mechanical properties by the formation of $\mathrm{Al}_{3} \mathrm{Er}$ [6-8]. A recent study reports that there is a synergetic effect of $\mathrm{Zr}$ and $\mathrm{Er}$ on the precipitation hardening of $\mathrm{Al}-\mathrm{Er}-\mathrm{Zr}$ alloy [9]. Li and coworks [10] also found that the recrystallization temperature of the Al-Er-Zr alloy is significantly higher than that of $\mathrm{Al}-\mathrm{Er}$ alloy, owing to the presence of nanosized and coherent $\mathrm{Al}_{3}(\mathrm{Er}, \mathrm{Zr})$ precipitates. In this paper, we focus on quaternary Al-Mg-Er-Zr alloy and investigate the precipitates strength and the subsequent effect on recrystallization resistance after cold rolling.

\section{Experimental materials and methods}

The experimental alloys were prepared through a conventional melting $\left(780^{\circ} \mathrm{C}\right)$ and casting $\left(720^{\circ} \mathrm{C}\right)$ route. The composition of the alloys, analysed by X-Ray Fluorescence(XRF), is given in Table 1 . The as-cast alloys were annealed in air isochronally from $150^{\circ} \mathrm{C}$, terminating at $550^{\circ} \mathrm{C}$, with increments of $25^{\circ} \mathrm{C}$, each lasting $3 \mathrm{~h}$. After isochronally annealing,the peak annealed samples were cold-rolled to $80 \%$ reduction. Then the as-rolled samples were annealed in air at temperatures between $125^{\circ} \mathrm{C}$ and $525^{\circ} \mathrm{C}$, at increments of $50^{\circ} \mathrm{C}$, and at each temperature point the samples were isothermally aged for $1 \mathrm{~h}$.

The Vickers microhardness was measured on polished samples with a load of $200 \mathrm{~g}$ and a dwell time of $10 \mathrm{~s}$. Samples polished using standard metallographic techniques and etched with Keller reagent were used for optical microscopy $(\mathrm{OM})$ characterization. Thin foils for TEM observation were prepared by twin-jet polishing with an electrolyte solution consisting of $25 \% \mathrm{HNO} 3$ and $75 \%$ methanol at $-30^{\circ} \mathrm{C}$. The specimens were analyzed using a JEOL 2100 microscope with an operating voltage of $200 \mathrm{kV}$. 
Table 1. Chemical composition of the alloys (wt.\%).

\begin{tabular}{lllll}
\hline Material & $\mathrm{Mg}$ & $\mathrm{Er}$ & $\mathrm{Zr}$ & $\mathrm{Al}$ \\
\hline $\mathrm{Al}-5 \mathrm{Mg}$ & 5.1 & 0 & 0 & Balance \\
$\mathrm{Al}-5 \mathrm{Mg}-0.3 \mathrm{Er}-0.25 \mathrm{Zr}$ & 4.8 & 0.29 & 0.25 & Balance \\
\hline
\end{tabular}

\section{Results and Discussion}

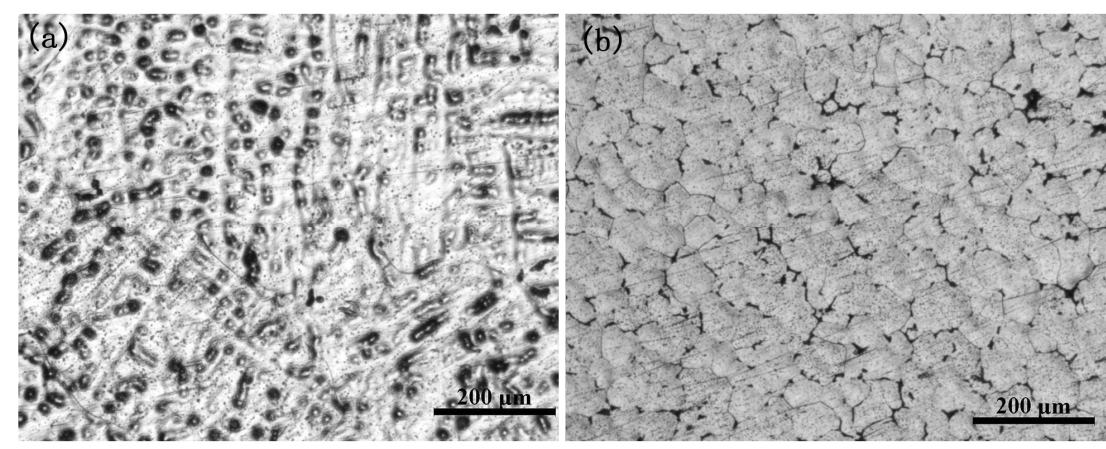

Fig. 1. As-cast microstructures of the alloys: (a) Optical microstructures of the Al-Mg alloy;(b)Optical microstructures of the Al-Mg-Er-Zr alloy

Microstructure of as-cast alloys. The microstructures of the as-cast Al-Mg alloys are shown in Fig. 1. It can be seen that an dendritic structure, which is the result of segregation of solute at the interdendritic regions, in the Al-Mg alloy. But the grains were refined and dendrite structures disappeared by the addition of Er and $\mathrm{Zr}$ simultaneously. Previous research also had shown that with addition of Er alone can refine the dendrite structures but can not eliminate it completely. This indicates that by joint addition of $\mathrm{Zr}$ and $\mathrm{Er}$ have a stronger refining effect than addition of $\mathrm{Er}$ singlely.
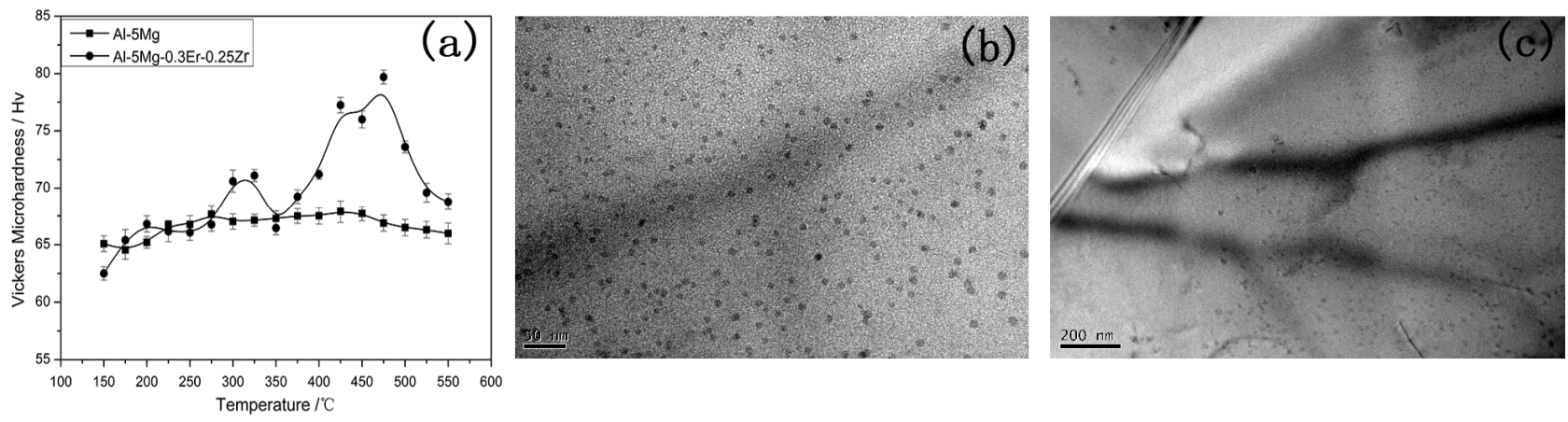

Fig. 2. The hardness curve of isochronal annealing(a) and the TEM micrograph of Al-Mg-Er-Zr alloy at the hardness peak value(b),(c).

Precipitation hardening. Fig. 2.(a) displays the hardness evolution of $\mathrm{Al}-\mathrm{Mg}$ and $\mathrm{Al}-\mathrm{Mg}-\mathrm{Er}-\mathrm{Zr}$ alloys during isochronal annealing. The Al-Mg alloy has no annealing hardening effect, its hardness remaining almost constant for all temperatures. The hardness of Al-Mg-Er-Zr alloy has a very significant annealing strengthening effect due to produce the second phase, $\mathrm{Al}_{3}(\mathrm{Er}, \mathrm{Zr})$, in the matrix. The hardness of Al-Mg-Er-Zr reaches the first peak of about $70 \mathrm{Hv}$ between 300 and $325^{\circ} \mathrm{C}$, then has a slightly decreases between 325 and $350^{\circ} \mathrm{C}$. The hardness of $\mathrm{Al}-\mathrm{Mg}$-Er- $\mathrm{Zr}$ reaches the senond peak of about $80 \mathrm{Hv}$ between 425 and $475^{\circ} \mathrm{C}$. Due to the relative high diffusivity of Er in a-Al, so $\mathrm{Al} 3 \mathrm{Er}$ firstly precipitate from $\alpha$-Al matrix between 300 and $325^{\circ} \mathrm{C}$. On the other hand due to a synergetic effect of $\mathrm{Zr}$ and $\mathrm{Er}$ on the precipitation hardening, the remaining Er can stimulate the decomposition of $\mathrm{Zr}$ and lead to a significant anneal hardening between 425 and $475^{\circ} \mathrm{C}$.

The TEM observations of Al-Mg-Er-Zr alloy after isochronal annealing to $475^{\circ} \mathrm{C}$ are shown in Fig. 2.(b),(c) Fine dispersed precipitates were observed in the Al-Mg-Er-Zr alloy. According to former study these precipitates should be $\mathrm{Al}_{3}(\mathrm{Er}, \mathrm{Zr})$. The precipitates are homogeneously distributed in the intergrain area, but at the grain boundary there exist a precipitates free zone which indicates that due to form some primary phase at the grain boundary thereby the content of solute atoms in the matrix decrease. The average radius of these small precipitates is about $10 \mathrm{~nm}$. In this 
size these small precipitates should be coherent with the matrix. So these precipitates can leads to the very significant annealing strengthening effect.
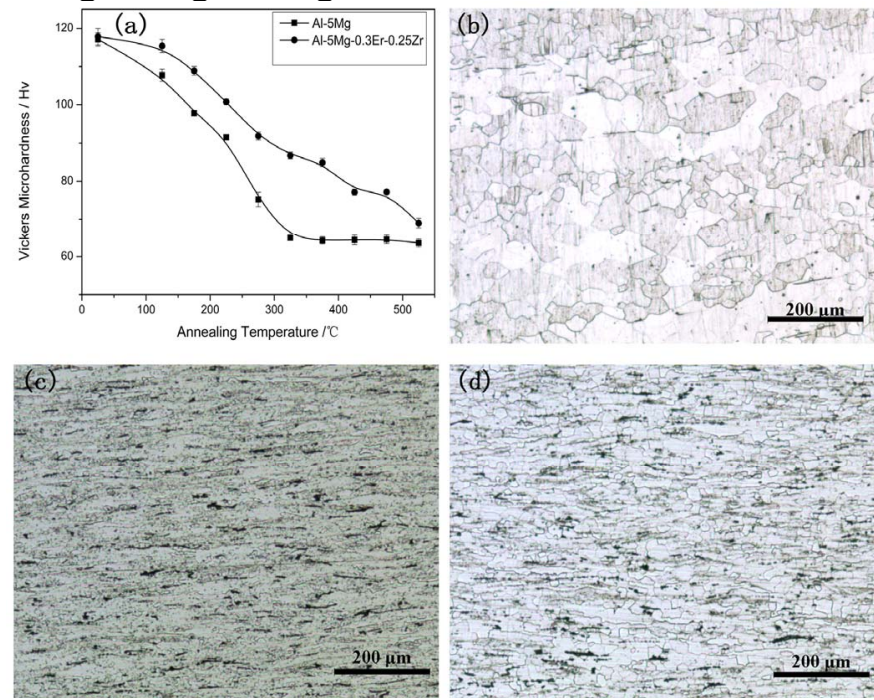

Fig. 3. (a) Hardness as a function of annealing temperature for $\mathrm{Al}-\mathrm{Mg}$ and $\mathrm{Al}-\mathrm{Mg}-\mathrm{Er}-\mathrm{Zr}$ alloys and micrographs of the cold-rolled alloys; (b) Al-Mg alloy annealed at $325^{\circ} \mathrm{C}$ for $1 \mathrm{~h}$; (c) $\mathrm{Al}-\mathrm{Mg}-\mathrm{Er}-\mathrm{Zr}$ alloy annealed at $375^{\circ} \mathrm{C}$ for $1 \mathrm{~h}(\mathrm{~d}) \mathrm{Al}-\mathrm{Mg}-\mathrm{Er}-\mathrm{Zr}$ alloy annealed at $525^{\circ} \mathrm{C}$ for $1 \mathrm{~h}$

Recrystallization Resistance. For investigating the recrystallization resistance of alloys, the cold-rolled samples were annealed in the temperature range of $125-525{ }^{\circ} \mathrm{C}$, at increments of $50{ }^{\circ} \mathrm{C}$, and at each temperature point the samples were isothermally annealed for $1 \mathrm{~h}$. Fig. 3.(a) shows the average microhardness of cold-rolled Al-Mg and Al-Mg-Er-Zr alloys as a function of temperature. It may be seen that the hardness of Al-Mg-Er-Zr alloy declines slowly with increasing the annealing temperature while that of Al-Mg alloy declines obviously from $225^{\circ} \mathrm{C}$ to $325^{\circ} \mathrm{C}$. The annealed microstructures of cold-rolled Al-Mg and Al-Mg-Er-Zr alloys are compared in Fig. 3.(b),(c),(d). It can be seen that Al-Mg alloy is fully recrystallized after annealing at $325^{\circ} \mathrm{C}$ for $1 \mathrm{~h}$, whereas Al-Mg-Er-Zr alloy basically keeps a fibrous structure after annealing at $375^{\circ} \mathrm{C}$ for $1 \mathrm{~h}$, which corresponds to the difference in hardness between $\mathrm{Al}-\mathrm{Mg}$ and $\mathrm{Al}-\mathrm{Mg}-\mathrm{Er}-\mathrm{Zr}$ alloys. The microhardness of Al-Mg alloy decreases to $65 \mathrm{Hv}$ at $325^{\circ} \mathrm{C}$, while Al-Mg-Er-Zr maintains a relatively high microhardness of $85.1 \mathrm{Hv}$ at $375^{\circ} \mathrm{C}$. Al-Mg-Er-Zr alloy displays a partially unrecrystallized structure even at $525^{\circ} \mathrm{C}$.In present $\mathrm{Al}-\mathrm{Mg}$-Er-Zr alloy, due to the addition of Er and $\mathrm{Zr}$ can form $\mathrm{Al}_{3}(\mathrm{Er}, \mathrm{Zr})$ precipitates during isochronal annealing. The $\mathrm{Al}_{3}(\mathrm{Er}, \mathrm{Zr})$ precipitates with large number density and small radius, should be favored to attain a large Zener drag which retards the movement of dislocation and subgrain boundaries. Thus the Al-Mg-Er-Zr alloy possess remarkable recrystallization resistance as compared with $\mathrm{Al}-\mathrm{Mg}$ alloy, which shows great potential for the development of thermally stable aluminum alloys.

\section{Sumary}

The combined addition of $\mathrm{Er}$ and $\mathrm{Zr}$ to Al-Mg alloy results in dramatically refining effect, significant precipitation strengthening effect and remarkable recrystallization resistance. The recrystallization temperature of the Al-Mg-Er-Zr alloy is significantly higher than that of $\mathrm{Al}-\mathrm{Mg}$ alloy, this can be attributed to the tiny and coherent $\mathrm{Al}_{3}(\mathrm{Er}, \mathrm{Zr})$ precipitates, which precipitation during isochronal annealing.

\section{Acknowledgements}

This work was supported in part by the National Key Basic Research\& Development Plan Project (No. 2012CB619503), National and Beijing Natural Science Foundation Project (No. 51201003 and No. 2142007), the National High Technology Research and Development Program (No. 2013AA031301). 


\section{References}

[1] L.F. Mondolfo: Aluminum Alloys: Structure and Properties (Butterworths Publications, Boston,1976).

[2] M. Popovic, E. Romhanji, J. Mater: Proc. Technol. Vol. 125-126 (2002), p. 275-280

[3] Willey, L.A, U.S. Patent 3,619,181. (1971)

[4] ZAKHAROV V V: Met. Sci. Heat. Treat. Vol. 45 (2003), p. 246-253

[5] RØYSET J, RYUM N: Int. Mater. Rev. Vol. 50(1) (2005), p. 9-44

[6] Z.R. Nie, T.N. Jin, J.B. Fu, G.F. Xu, J.J. Yang, J.X.Zhou, T.Y. Zuo: Mater. Sci. Forum Vol.396-402 (2002), p. 1731

[7] Z.R. Nie, T.N. Jin, J.X. Zou, J.B. Fu, J.J. Yang, T.Y.Zuo: Trans. Nonferrous Met. Soc. China Vol.13 (2003), p. 509

[8] S.P. Wen, Z.B. Xing, H. Huang, B.L. Li, W. Wang, Z.R.Nie: Mater. Sci. Eng. A Vol. 516 (2009) p. 42

[9] S.P. Wen, K.Y. Gao, Y. Li, H. Huang, Z.R. Nie: Scripta Mater. Vol. 65 (2011), p. 592-595

[10]H.Y Li, Z.H Gao,H Yin, H.F Jiang,a X.J Sua and J Bin: Scripta Mater. Vol. 68 (2013), p. 59-62 